Article

\title{
Impact of Standardized Prenatal Clinical Training for Traditional Birth Attendants in Rural Guatemala
}

\author{
Sasha Hernandez ${ }^{1, *}$, Jessica Oliveira ${ }^{1}$, Leah Jones ${ }^{1}$, Juan Chumil ${ }^{2}$ and Taraneh Shirazian ${ }^{1}$ \\ 1 Saving Mothers, New York, NY 10022, USA; joliveira@savingmothers.org (J.O.); \\ ljones@savingmothers.org (L.J.); tshirazian@savingmothers.org (T.S.) \\ 2 Ministerio de Salud Pública y Asistencia Social, Santiago Atitlán, Sololá 07019, Guatemala; \\ jchumilcuc@hotmail.com \\ * Correspondence: shernandez@savingmothers.org; Tel.: +1-954-993-6017
}

Received: 24 April 2018; Accepted: 6 June 2018; Published: 9 June 2018

\begin{abstract}
In low-and-middle-income countries (LMICs), traditional birth attendant (TBA) training programs are increasing, yet reports are limited on how those programs affect the prenatal clinical abilities of trained TBAs. This study aims to assess the impact of clinical training on TBAs before and after a maternal health-training program. A prospective observational study was conducted in rural Guatemala from March to December 2017. Thirteen participants conducted 116 prenatal home visits. Data acquisition occurred before any prenatal clinical training had occurred, at the completion of the 14-week training program, and at six months post program completion. The paired $t$-test and McNemar's test was used and statistical analyses were performed with R Version 3.3.1. There was a statistically significant improvement in prenatal clinical skills before and after the completion of the training program. The mean percentage of prenatal skills done correctly before any training occurred was $25.8 \%, 62.3 \%$ at the completion of the training program ( $p$-value $=0.0001)$, and $71.0 \%$ after six months of continued training $(p$-value $=0.034)$. This study highlights the feasibility of prenatal skill improvement through a standardized and continuous clinical training program for TBAs. The improvement of TBA prenatal clinical skills could benefit indigenous women in rural Guatemala and other LMICs.
\end{abstract}

Keywords: birth attendant; prenatal care; clinical skills; education; maternal mortality; indigenous health; rural; Guatemala

\section{Introduction}

Significant worldwide progress has been made towards lowering rates of maternal mortality in the last two decades [1]. Yet maternal mortality ratios (MMR) in the developing world, especially in rural regions and within indigenous populations, continue to be unacceptably high [2]. This holds true in Guatemala where the national average of 88 maternal deaths per 100,000 births [1] does not reflect the major disparities that exist between the MMR for indigenous women which is twice that of their counterparts (163 per 100,000 compared to 78 per 100,000) [3]. In recent years, the Guatemalan government has aimed to decrease this discrepancy by promoting institutional births [4], however, up to $70 \%$ of indigenous women living in rural Guatemala continue to deliver at home without receiving adequate prenatal care [5]. This continued preference of home care during pregnancy and delivery is due both due to limited access to essential obstetric care [6] and a non-wavering cultural preference for traditional birth attendants (TBAs) to attend to women at home [7].

TBAs are important to both the local community and national health infrastructure as their training and integration in the current healthcare system can help improve maternal and neonatal outcomes [8-11]. Despite the significant role TBAs hold, there are limitations, as few sustainable 
training programs exist that properly train TBAs in how to provide basic prenatal care, detect early complications, or refer high-risk pregnancies in a standardized way. TBA participants themselves report that they are not always given sufficient training during these programs [12]. Even for successful programs, challenges exist in measuring Prenatal Clinical Skills (PCS) and reporting trends over time. While some studies have attempted to evaluate PCS, they have focused on simulated sessions [13] and cross-sectional views [14]. Such studies do not provide a direct look at how a training program affects the PCS of their trainees before and after training and how those skills develop after continued training.

The School of POWHER, which stands for Providing Outreach in Women's Health and Educational Resources, is a yearly TBA training program that has been successfully implemented in the rural communities of the department of Sololá, Guatemala over the last four years and supported by both community infrastructure and the regional branch of the Guatemalan Ministry of Health. The School of POWHER training program is an immersive program, delivered in both Spanish and Tz'tujil (a local Mayan language), based on a two-pronged approach. There is a 28-module lecture series (which runs over 14 weeks, with two four-hour lectures given per week) emphasizing signs of referrals for the mom and baby, prenatal care, and initial management of post-partum complications (Figure S1, see Supplementary Materials). A separate 12-month clinical constituent emphasizes basic prenatal home care and appropriate referral. The clinical arm of the school ensures that TBAs refine their traditional midwifery abilities while learning new skills under the supervision of a preceptor. During bi-monthly home visits in the students' communities over twelve months, the TBAs will practice items, including but not limited to, counseling the mother about vaccines, measuring blood pressure, using a fetal Doppler, and correctly estimating delivery date. The School of POWHER respects cultural Mayan practices and its content is in line with current WHO and Guatemalan healthcare guidelines for TBAs $[15,16]$. Each woman that completes the School of POWHER training program receives a stethoscope, blood pressure equipment, a fetal Doppler, prenatal vitamins, and safe birthing kits. In total, the training program, now a one hundred percent sustainable program as current School of POWHER staff are TBAs who are past graduates of our program, has trained 60 TBAs in southwest Guatemala in focused maternal healthcare with appropriate obstetric referrals as the key to decreasing maternal death and complications in the region [17].

The main objective of the present study was to assess the effect of the School of POWHER's clinical training on its participants after (1) completion of the program and (2) after six months of continued clinical training. The time of notable improvement of PCS, as well as level of adherence over time, was also studied.

\section{Materials and Methods}

A community-based, prospective observational study was conducted in six rural communities throughout the department of Sololá, Guatemala from March through December 2017 to assess direct PCS acquisition and retention from the School of POWHER training program during prenatal home visits.

All TBAs recruited and then enrolled in the School of POWHER training program during the time of this study were included. TBA demographics are described in Table 1.

Table 1. Traditional birth attendant participant demographics.

\begin{tabular}{ccc}
\hline Characteristic & Average & Range \\
\hline Age & 40 & $22-54$ \\
\hline Level of Education & $2^{\text {nd }}$ grade & $\begin{array}{c}\text { No formal education-8th grade (one outlier with one } \\
\text { participant pursuing a technical degree in nutrition) }\end{array}$ \\
\hline Marital Status & Married & 1 single, 1 widowed, 11 married \\
\hline Years of Experience & 9 & $0-27$ \\
\hline Dominant Language & Spanish, Tz'tujil, Kaqcuichel & \\
\hline
\end{tabular}


Data collection was scheduled at three different time points from March through December 2017 with the goal of capturing PCS during home visits prior to and after School of POWHER clinical training. Home visits were arranged with each TBA student in their respective communities with their existing patients. If a TBA student did not have current pregnant patients and/or a visit could not be scheduled with her patient, the Ministry of Health provided a list of pregnant women in each community to visit. Each time point and the corresponding amount of clinical training are defined in Table 2. The goal was to observe 1-5 prenatal home visits by each TBA student in their own community during each of the three time points. Two weeks were allotted after each time point to collect all observational data from the 13 TBA participants. During each two-week data collection time point, no additional clinical instruction occurred to ensure that each participant had received the same amount of clinical training.

Table 2. The data collection characteristics.

\begin{tabular}{cccc}
\hline Study Time Point & Dates of Data Collection & $\begin{array}{c}\text { Total Weeks of } \\
\text { Clinical Training }\end{array}$ & $\begin{array}{c}\text { Total Weeks of } \\
\text { Knowledge-Based Learning }\end{array}$ \\
\hline Time Point A & March 22-April 7, 2017 & 0 & 0 \\
Time Point B $^{2}$ & June 30-August 16, 2017 & 14 & 14 \\
Time Point C $^{3}$ & November 7-December 12, 2017 & 38 & 14 \\
\hline
\end{tabular}

1 Time point A occurred before any clinical instruction had begun; ${ }^{2}$ Time point B occurred at the completion of 14-weeks of formalized POWHER curriculum; ${ }^{3}$ Time point $C$ occurred after six months of continuous clinical training from completion of the formalized POWHER curriculum.

During each time point of the study period, prenatal home visits were observed with a WHO-adapted prenatal care checklist tested in our prior pilot study [18]. This WHO-adapted checklist covered three broad categories of medical history, clinical skills, and counseling (Figure S2, see Supplementary Materials). The medical history information included age, number of previous pregnancies, complications with previous pregnancies, other significant medical history, current medications, current weeks of gestation, and estimated date of delivery. The clinical skills evaluated included measuring the maternal blood pressure, fundal height, fetal heart rate, and fetal position. Counseling included reviewing signs and symptoms of danger during pregnancy and what course of action to take if danger symptoms presented. A review of the emergency birth plan, the importance of tetanus vaccination, and prenatal vitamins were also evaluated. All study variables and appropriate reasons for referrals are defined in Table 3.

Table 3. The variables included in the prenatal clinical skills observation checklist.

\begin{tabular}{lll}
\hline \multicolumn{1}{c}{ Variable } & \multicolumn{1}{c}{ Definition } & \multicolumn{1}{c}{ Reason for Referral } \\
\hline History & & \\
\hline Accurately calculates EDD & Using Naegele's rule or pregnancy wheel. & If LMP unknown, referral for dating US. \\
\hline Accurately calculates GA & Only if the mother knows LMP. & If LMP unknown, referral for dating US. \\
\hline Age & $\begin{array}{l}\text { Asks mother for an identification card if age } \\
\text { is not known. }\end{array}$ & $\begin{array}{l}\text { Referral recommended if AMA or less than } \\
\text { 16 years old. }\end{array}$ \\
\hline \# of previous pregnancies & All pregnancies, including miscarriages. & \\
\hline \# of living children & $\begin{array}{l}\text { All children; follows up if there is a } \\
\text { discrepancy between total pregnancies and } \\
\text { living children. }\end{array}$ & $\begin{array}{l}\text { Asks about prolonged labor, hemorrhage, } \\
\text { problems with blood pressure, severe } \\
\text { headache, fever during or after labor, } \\
\text { infection during or after labor, prior } \\
\text { Problems with previous } \\
\text { pregnancies }\end{array}$ \\
$\begin{array}{ll}\text { C-sections. } \\
\text { Past medical history }\end{array}$ & $\begin{array}{l}\text { Assesses any health conditions outside of } \\
\text { pregnancy. }\end{array}$ & $\begin{array}{l}\text { from current pregnancy recommends } \\
\text { hospital birth. }\end{array}$ \\
\hline $\begin{array}{l}\text { Current medications } \\
\text { Assesses both OTC medications and street } \\
\text { supplements. }\end{array}$ & \\
\hline
\end{tabular}


Table 3. Cont.

\begin{tabular}{|c|c|c|}
\hline Variable & Definition & Reason for Referral \\
\hline Documents history & $\begin{array}{l}\text { Variables of importance are name, age, EDD, } \\
\text { and prior issues of importance in order to } \\
\text { report to the MOH. Not applicable for } \\
\text { illiterate TBA. }\end{array}$ & \\
\hline \multicolumn{3}{|l|}{ Clinical skills } \\
\hline Washes hands & Uses soap and water or antiseptic solution. & \\
\hline Measures blood pressure & $\begin{array}{l}\text { Mother seated or supine, arm below the heart, } \\
\text { places cuff } 1-2 \text { finger breadths above the } \\
\text { elbow, places stethoscope in the area of the } \\
\text { brachial artery under the cuff. }\end{array}$ & $\begin{array}{l}\text { Refers if blood pressure greater than } 140 / 90 \text {, } \\
\text { or in "red zone" if illiterate TBA. }\end{array}$ \\
\hline Measures heart rate & Locates radial pulse and measures for $60 \mathrm{~s}$. & \\
\hline Measures fundal height & $\begin{array}{l}\text { Can use a measuring tape or hand } \\
\text { measurements if TBA is illiterate. }\end{array}$ & $\begin{array}{l}\text { Refers if there is a difference greater than } 4 \mathrm{~cm} \\
\text { from fundal height compared to GA. }\end{array}$ \\
\hline Listens to fetal heart rate & $\begin{array}{l}\text { Can find fetal heart rate and distinguish from } \\
\text { maternal heart rate and placental vessels. }\end{array}$ & $\begin{array}{l}\text { Refers if fetal distress }(\mathrm{FHR}>160 \mathrm{bpm}, \\
<100 \mathrm{bpm}) \text { persists throughout the visit. }\end{array}$ \\
\hline Finds the position of fetus & Uses Leopold's maneuvers. & $\begin{array}{l}\text { If the fetal position is oblique, transverse, } \\
\text { or breech, in late pregnancy, discusses with } \\
\text { mother the dangers of home birth. }\end{array}$ \\
\hline Documents all findings & $\begin{array}{l}\text { Variables of importance are blood pressure } \\
\text { findings to track trends over pregnancy, not } \\
\text { applicable if illiterate. }\end{array}$ & \\
\hline \multicolumn{3}{|l|}{ Counseling } \\
\hline $\begin{array}{l}\text { Discusses severe } \\
\text { headaches }\end{array}$ & $\begin{array}{l}\text { Explains to mom the risk of a severe } \\
\text { headache and associated changes in vision. }\end{array}$ & $\begin{array}{l}\text { Discusses with mother to report to the health } \\
\text { post, local hospital, or private clinic. }\end{array}$ \\
\hline $\begin{array}{l}\text { Discusses severe } \\
\text { abdominal pains }\end{array}$ & Demonstrates pain in the epigastric region. & $\begin{array}{l}\text { Discusses with mother to report to the health } \\
\text { post, local hospital, or private clinic. }\end{array}$ \\
\hline Discusses vaginal bleeding & $\begin{array}{l}\text { Explains the risk of spotting or bleeding at } \\
\text { any point during the pregnancy. }\end{array}$ & $\begin{array}{l}\text { Discusses with mother to report to the health } \\
\text { post, local hospital, or private clinic. }\end{array}$ \\
\hline Discusses fever & $\begin{array}{l}\text { Explains chills and night sweats as symptoms } \\
\text { of a fever. }\end{array}$ & $\begin{array}{l}\text { Discusses with mother to report to the health } \\
\text { post, local hospital, or private clinic. }\end{array}$ \\
\hline Discusses location of birth & $\begin{array}{l}\text { Discusses with mother and partner (if } \\
\text { present) about the risks and benefits of both a } \\
\text { home birth and a hospital birth). }\end{array}$ & \\
\hline Discusses emergency plan & $\begin{array}{l}\text { Discusses with mother and partner (if } \\
\text { present) where to report and how to get there } \\
\text { if an emergency arises during labor and } \\
\text { delivery. }\end{array}$ & \\
\hline $\begin{array}{l}\text { Distributes prenatal } \\
\text { vitamins }\end{array}$ & Hands a 30 day supply to mother. & \\
\hline $\begin{array}{l}\text { Counsels on the } \\
\text { importance of prenatal } \\
\text { vitamins }\end{array}$ & $\begin{array}{l}\text { Explains the maternal and fetal benefit of } \\
\text { prenatal vitamins to mother. }\end{array}$ & \\
\hline Counsels on Td vaccine & $\begin{array}{l}\text { Explains the vaccine schedule ( } 1^{\text {st }} \text { shot, } 2^{\text {nd }} \\
\text { shot } 2 \text { months later, } 3^{\text {rd }} \text { shot months later) to } \\
\text { mother and the importance of vaccination } \\
\text { especially if a home birth is planned. }\end{array}$ & $\begin{array}{l}\text { Refers to either health post or local hospital to } \\
\text { received Td vaccine. }\end{array}$ \\
\hline
\end{tabular}

Abbreviations: $\mathrm{EDD}=$ estimated delivery date; $\mathrm{GA}$ = gestational age; $\mathrm{LMP}=$ last menstrual period; $\mathrm{AMA}=$ advanced maternal age; OTC $=$ over the counter.

On arrival at each home, the evaluator observed the prenatal home visit after patient verbal consent was obtained from the TBA conducting the visit. During the data collection process, one of two evaluators observed all prenatal home visits. These two evaluators were trained on the POWHER curriculum and observation checklist before the commencement of the study. Evaluator A, a senior medical student, was in charge of data collection during the pilot study period to Time Point A. Evaluator B, a medical volunteer with public health experience, observed the prenatal home visits from Time Point B to Time Point C. A translator assisted the evaluator for visits that occurred in native 
languages (Tz'utujil and Kaqchikel). After the completion of the observed visit, the evaluator had an opportunity to intervene if maternal or fetal referral was indicated, but missed by the TBA during the observation. This referral was not included as part of this study. No personal patient identifiers were collected to maintain the confidentiality of the women.

Data analysis was carried out using standard statistical methods. The paired $t$-test and McNemar's test was used and statistical analyses were performed with R, Version 3.3.1 (R Core Team, Vienna, Austria).

\section{Results}

A total of 116 prenatal home visits by 13 TBAs were observed. Each TBA participant was evaluated at each of the three time points as no participants were lost to follow-up. A total of 59 visits occurred at Time Point A, 39 visits occurred at Time Point B, and 18 visits occurred at Time Point C. For TBAs with multiple observed home visits during each time point, their results were averaged over their visits (Figure 1).

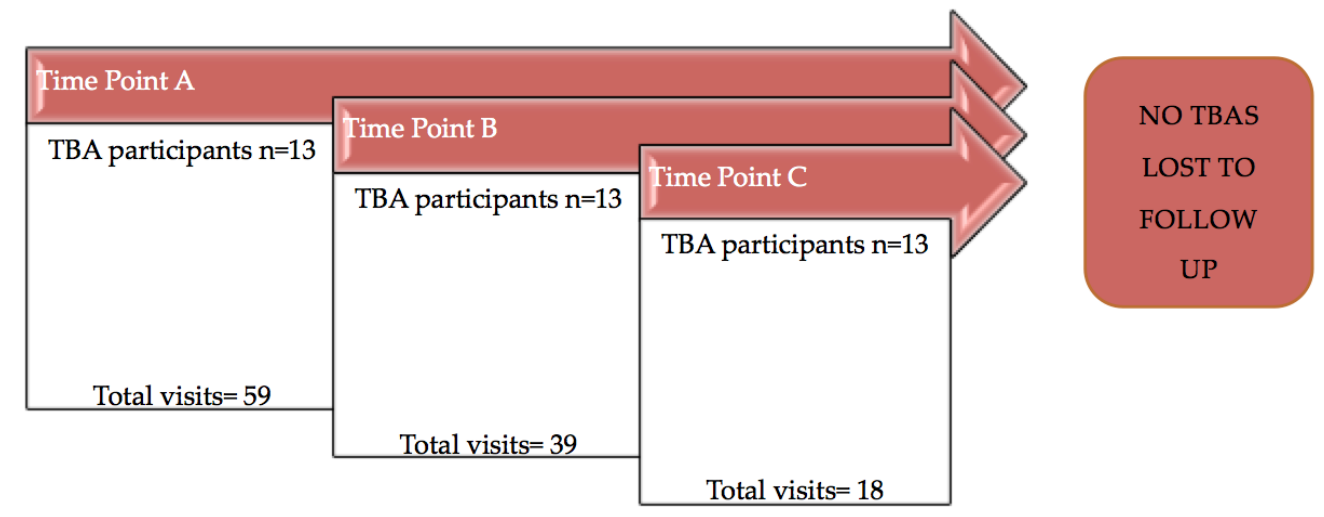

Figure 1. The total participants and observed visits over the study period.

No study participants were lost to follow up from March to December of 2017. Total observed visits differed from each of the three time points due to the difficulty in reaching each rural community due to nationwide transportation strikes. The median number of home visits per TBA during time point $A$ was 3 with a range of $1-9,2$ home visits per TBA during time point $B$ with a range of $1-8$, and 1 home visit per TBA during time point $C$ with a range of 1-3.

The overall improvement in prenatal clinical skills is shown in Table 4. The mean percentage correct on the checklist before any training occurred was $25.8 \%$ (Time Point A). The mean percentage correct on the checklist after the completion of the School was 62.3\% (Time Point B). There was also a statistically significant improvement between the completion of the School of POWHER (Time Point B), a mean of $62.3 \%$, and continued clinical training for 6 months following completion of the School of POWHER with a mean of $71.0 \%$ (Time Point C). The largest amount of overall checklist improvement was seen before any clinical training occurred (Time Point A) when compared to completion of the School of POWHER (Time Point B).

Specific improvement in each of the three prenatal skills categories was also statistically significant as seen in Table 5. In the category of history, taking the mean percentage correct on the checklist before any training occurred (Time Point A) was $26.3 \%$ compared to $58.8 \%$ at the completion of the School of POWHER ( $p$-value $=0.005)$ (Time Point B). After six months of continued clinical training from the completion of the School of POWHER (Time Point C), the percent correct on the checklist improved to $87.1 \%$ ( $p$-value $<0.0001$ ). In the category of clinical skills, the mean percentage correct on the checklist before any training occurred (Time Point A) was 9.7\% compared to $92.4 \%$ at the completion of the School of POWHER ( $p$-value $<0.0001$ ) (Time Point B). After six months of continued clinical training from the completion of the School of POWHER, the percent correct on the checklist was $81.4 \%$ (Time 
Point C). This decrease in overall percentage correct was not statistically significant $(p$-value $=0.19)$. In the category of counseling, the mean percentage correct on the checklist before any training occurred (Time Point A) was $27.7 \%$ compared to $86.2 \%$ at the completion of the School of POWHER ( $p$-value $<0.0001$ ) (Time Point B). After six months of continued clinical training from the completion of the School of POWHER (Time Point C), the percent correct in counseling on the checklist was $72.0 \%$. This decrease in overall percentage correct was also not statistically significant ( $p$-value $=0.09$ ).

Table 4. The overall improvements in prenatal clinical skills. ${ }^{1}$

\begin{tabular}{|c|c|c|c|c|}
\hline & Time Point $\mathrm{A}^{2}$ & Time Point $\mathrm{B}^{3}$ & Time Point $C^{4}$ & $p$-value ${ }^{5}$ \\
\hline $\begin{array}{l}\text { Percentage of correctly performed } \\
\text { prenatal clinical skills }\end{array}$ & $25.8(19.6)$ & $62.3(16.3)$ & $71(12.5)$ & $\begin{array}{c}\text { Between A and B, } 0.0001 \\
\text { Between B and C, } 0.034\end{array}$ \\
\hline
\end{tabular}

Table 5. The specific checklist improvements per category ${ }^{1}$

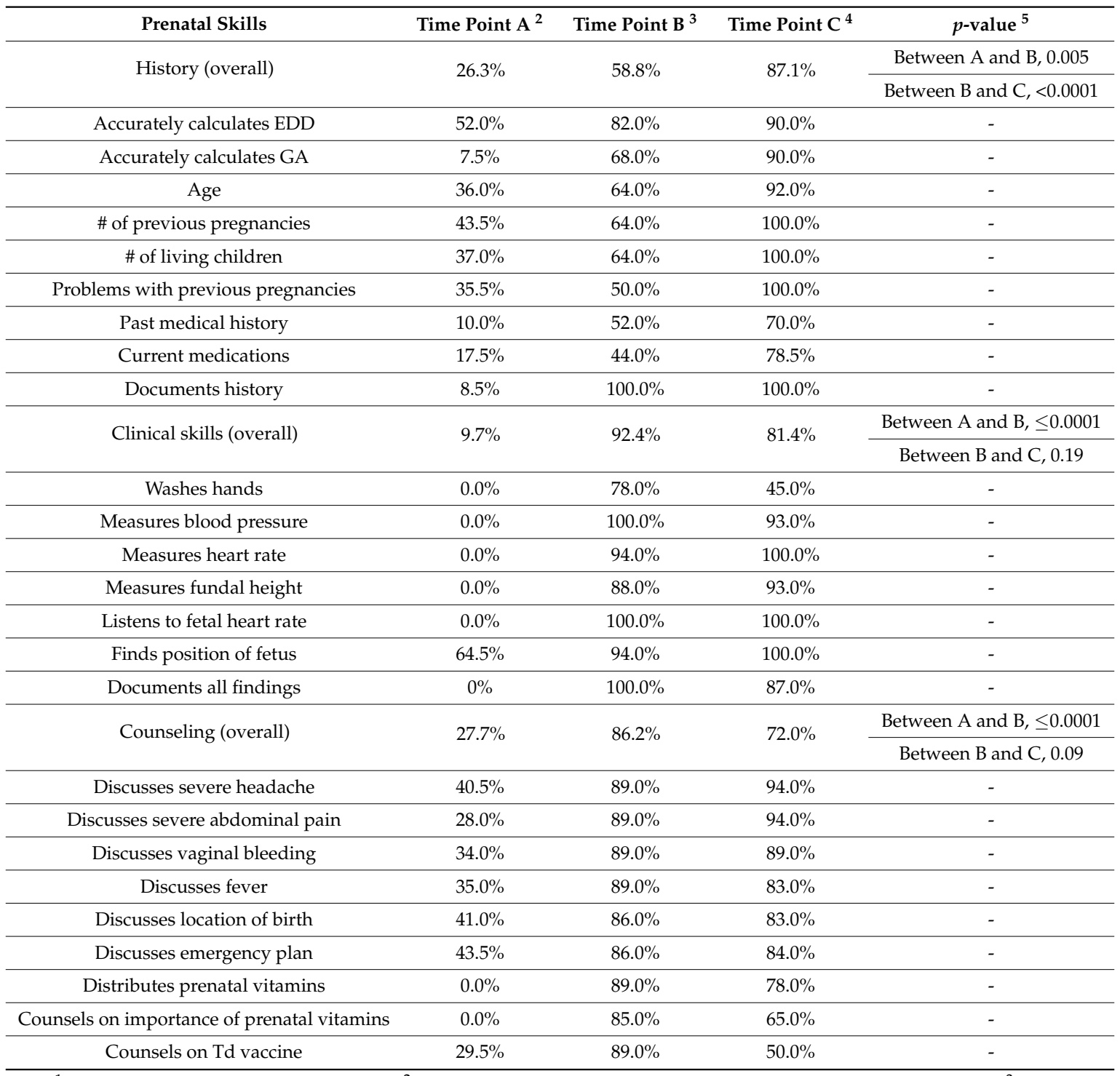

${ }^{1}$ Values entered as mean percentages; ${ }^{2}$ Time point A occurred before any clinical instruction had begun; ${ }^{3}$ Time point B occurred at the completion of 14-weeks of formalized POWHER curriculum; ${ }^{4}$ Time point $\mathrm{C}$ occurred after six months of continuous clinical training from completion of the formalized POWHER curriculum; ${ }^{5}$ Paired $t$-test. 
The number of referrals increased over the study period although statistically insignificant. Before any clinical training occurred (Time Point A), only $17.8 \%$ of women were referred correctly. At the completion of the School of POWHER (Time Point B), appropriate referrals increased to $52.0 \%(p=0.32$ ). After six months of continued clinical training from the completion of the School of POWHER (Time Point C), appropriate referrals from the clinical checklist was $27.7 \%$. The largest increase in referrals was seen in the category of clinical skills most commonly referred for the malposition of the fetus during late pregnancy.

\section{Discussion}

When TBA training is successfully implemented in rural communities, TBAs increase their basic obstetric knowledge, are equipped for safe home deliveries, and are able to identify problems requiring a referral; factors which markedly improve obstetrical outcomes [19]. Recent systematic reviews have identified that successful programs are those that can be integrated into an existing healthcare system, continue skill development (monthly or bi-monthly) of its participants for an extended period of time, and provides them access to birth kits and resuscitation equipment $[9,10,12,20]$.

Our study, in line with these systematic reviews, suggests that standardized and continuous clinical training improves the PCS of TBAs during home visits. Overall, our TBAs were more likely to provide more complete prenatal home visits after the completion of School of POWHER training. An improvement was seen consistently in each broad category (history, clinical skills, and counseling) of basic prenatal care. Continued improvement was seen after six months of post School of POWHER clinical training (10-months of overall clinical training). The finding of this present study are generally encouraging as other studies, including our own previous pilot study, have demonstrated that a lack of continuous training leads to a decrease in PCS [18]. This point is of utmost importance as many TBA programs in low-and-middle-income countries fail to provide follow-up training after the completion of their training program. We have demonstrated how PCS continue to improve, and the average amount of improvement expected to be seen within each broad category of prenatal care, when clinical training is structured and continuous.

One of the biggest challenges that TBA training programs face is successfully measuring and reporting the outcomes of their didactic and clinical curriculum. We have previously published on the details of our 14-week School of POWHER training program [17]. With this present study, we focus on the standardization of our clinical curriculum and measuring its impact on PCS of our participant with a prenatal skills checklist. Our choice of standardization of clinical skills through a checklist was influenced by the success of other checklists in maternal healthcare [21-23]. The initial development of our prenatal skills checklist occurred from November 2016 through March 2017. Our own School of POWHER curriculum [17], WHO healthcare practices for birth attendants [15], and current guidelines for TBAs from the Guatemalan Ministry of Health [16] were consulted. By using this checklist to both standardize our clinical curriculum and measure PCS over time, we were able to report on a promising improvement of PCS during home visits. We believe our checklist had this effect via two ways: (1) our educators who trained the TBAs had an easy instrument that highlighted the key aspects of prenatal care from the clinical curriculum, (2) our TBAs had a simple and systematic approach during their prenatal home visits that reflected the curriculum learned during their training. Ultimately, the prenatal checklist standardized the clinical curriculum and successfully measured PCS improvement of each participant.

Additionally, the results of our study demonstrated the referral capacities of our TBAs throughout their training. Our study participants saw a significant increase in appropriate referrals after the completion of the School of POWHER training program (Time Point B). Referrals decreased after six months of continuous, focused PCS training (Time Point C) but remained higher than referral capacities when TBAs had no training at all (Time Point A). It is likely that there was a decrease in referrals from Time Point $B$ to Time Point $C$ due to the strong emphasis on standardized PCS training during this six month time period. During this period, there was focused exposure and training on PCS 
where referral teaching by the clinical educators was not as structured. Furthermore, study observers reported that during time Point $C$, study participants verbalized that they were more comfortable waiting on certain referral points until the mother was more advanced in her pregnancy (for example maternal age or past medical history), thus, the study tool would not pick up this later referral as it was not captured during the observed visit. Despite this, even at Time Point B, when the most referrals were occurring by study participants, only $52 \%$ of women were accurately referred. Our study suggests that a major focus on PCS during continued training does not indicate an equivalent increase in referrals. Our results on referral capacities also demonstrate the need to have a structured teaching approach for referrals taught parallel to standardized PCS.

This latter point is key as referrals must be timely and appropriate, which will only occur with access to properly trained birth attendants. Despite the push towards institutionalized births, the WHO has recognized that quality care during labor and delivery does not necessarily occur once a birth occurs in a hospital [24]. Specifically in Guatemala where there has been a push to birth in hospitals [4], untimely referrals during pregnancy by untrained healthcare personnel has inundated hospital waiting rooms leading to a minimal decrease in MMR. A possible solution to this problem lies in a new model of Birthing Homes (Casa Maternas) which have helped to reduce inappropriate referrals to the national hospitals in Guatemala [25]. This effective hybrid model between a home and institutional birth relies on the referral capacities of trained birth attendants that run the birthing homes. We propose that effective clinical training of TBAs not only affects the healthcare of women in rural settings but also has a larger impact on the burden of institutional births.

Findings from our study should be interpreted within its limitations. Our sample size of 13 TBA participants was small. Nonetheless, our study was able to capture each participant before and after exposure to the School of POWHER training program and follow PCS outcomes over a considerable amount of time as the last data collection point was at eight and a half months of total clinical training. The small sample size potentially affected our statistical analysis of referrals performed by our TBA study participants, as the analytic sample at Time Point $C$ is approximately $1 / 3$ of the analytical sample at Time Point B and C. This difference in an already small sample size could mean that it is possible that there is not a sufficient sample size to detect subtle improvements in accurate referrals. Convenience sampling may introduce study bias but was unavoidable in the current study as it was extremely difficult to recruit and observe TBAs that were not participating in the School of POWHER training program. Additionally, participants knew that they were being observed and this could have unintentionally influenced their behavior during prenatal home visits. Participants might have been driven to practice the PCS they learned during the training program when the observer was present but this does not indicate that TBA participants were routinely implementing PCS during routine unobserved home visits.

Despite these limitations, the strength and originality of our study counteracts many of the biases put forth. Our standardization of prenatal clinical care and subsequent measurement of PCS prior to and after our training program via observation allows for a direct method to collect data that is superior to self-reporting.

\section{Conclusions}

This study highlights the feasibility of PCS improvement through a standardized and continuous clinical training program for TBAs. The prenatal checklist assessment tool also serves as an objective means to quantify TBA skills in order to evaluate and maintain their skills in low resource settings. The improvement of TBA prenatal clinical skills could benefit indigenous women in rural Guatemala, and other low-and middle-income countries that prefer and/or have no other option except home care during pregnancy and birth.

Supplementary Materials: The following are available online at http:/ /www.mdpi.com/2227-9032/6/2/60/s1, Figure S1: The School of POWHER curricular overview, Figure S2: Prenatal Clinical Assessment Tool. 
Author Contributions: S.H. helped with the implementation of the training program and clinical study, acquired and analyzed study data, drafted, and revised the manuscript. J.O. contributed to the conception, initial development, and implementation of the training program and the initial development of the clinical study. J.C. helped with the implementation of the training program and clinical study and recruitment of study participants. L.J. helped with the implementation of the clinical study, and acquired and analyzed study data. T.S. contributed to the initial conception and development of the training program, the design and implementation of the clinical study, and revised the manuscript. All authors approve the manuscript.

Acknowledgments: Financial support was provided by a Global Health Education Grant from the Consortium of Universities for Global Health.

Conflicts of Interest: The authors declare no conflict of interest.

\section{References}

1. Alkema, L.; Chou, D.; Hogan, D.; Zhang, S.; Moller, A.B.; Gemmill, A.; Fat, D.M.; Boerma, T.; Temmerman, M.; Mathers, C.; et al. Global, regional, and national levels and trends in maternal mortality between 1990 and 2015, with scenario-based projections to 2030: A systematic analysis by the UN Maternal Mortality Estimation Inter-Agency Group. Lancet 2016, 387, 462-474. [CrossRef]

2. Zureick-Brown, S.; Newby, H.; Chou, D.; Mizoguchi, N.; Say, L.; Suzuki, E.; Wilmoth, J. Understanding Global Trends in Maternal Mortality. Int. Perspect. Sex Reprod. Health 2013, 39, 32-41. [CrossRef] [PubMed]

3. MSPAS. Estudio Nacional de Mortalidad Materna 2011. Guatemala City. 2011. Available online: http:/ / www.mspas.gob.gt/index.php/component/jdownloads/send/94-muerte-materna/805estudio-nacional-de-mortalidad-materna-2011?option=com_jdownloads (accessed on 28 September 2016).

4. Walton, A.; Kestler, E.; Dettinger, J.C.; Zelek, S.; Holme, F.; Walker, D. Impact of a low-technology simulation-based obstetric and newborn care training scheme on non-emergency delivery practices in Guatemala. Int. J. Gynaecol. Obstet. 2016, 132, 359-364. [CrossRef] [PubMed]

5. Ministerio de Salud Publica y Asistencia Social. Encuesta Nacional de Salud Materno Infantil: Informe Interno Priliminario; Ministerio de Salud Publica y Asistencia Social: Guatemala City, Guatemala, 2017.

6. Bailey, P.E.; Szaszdi, J.A.; Glover, L. Obstetric complications: Does training traditional birth attendants make a difference. Rev. Panam. Salud Publica 2002, 11, 15-23. [CrossRef] [PubMed]

7. Walsh, L. Beliefs and rituals in traditional birth attendant practice in Guatemala. J. Transcult. Nurs. 2006, 17, 148-152. [CrossRef] [PubMed]

8. Mahler, H. The safe motherhood initiative: A call to action. Lancet 1987, 1, 668-670. [CrossRef]

9. Byrne, A.; Morgan, A. How the integration of traditional birth attendants with formal health systems can increase skilled birth attendance. Int. J. Gynaecol. Obstet. 2011, 115, 127-134. [CrossRef] [PubMed]

10. Wilson, A.; Gallos, I.D.; Plana, N.; Lissauer, D.; Khan, K.S.; Zamora, J.; MacArthur, C.; Coomarasamy, A. Effectiveness of strategies incorporating training and support of traditional birth attendants on perinatal and maternal mortality: Meta-analysis. BMJ 2011, 343. [CrossRef] [PubMed]

11. Sakala, C.; Newburn, M. Meeting needs of childbearing women and newborn infants through strengthened midwifery. Lancet 2014, 384, e39-e40. [CrossRef]

12. Munabi-Babigumira, S.; Glenton, C.; Lewin, S.; Fretheim, A.; Nabudere, H. Factors that influence the provision of intrapartum and postnatal care by skilled birth attendants in low- and middle-income countries: A qualitative evidence synthesis. Cochrane Database Syst. Rev. 2017, 11, Cd011558. [CrossRef] [PubMed]

13. Carlough, M.; McCall, M. Skilled birth attendance: What does it mean and how can it be measured? A clinical skills assessment of maternal and child health workers in Nepal. Int. J. Gynaecol. Obstet. 2005, 89, 200-208. [CrossRef] [PubMed]

14. Ayiasi, R.M.; Criel, B.; Orach, C.G.; Nabiwemba, E.; Kolsteren, P. Primary healthcare worker knowledge related to prenatal and immediate newborn care: A cross sectional study in Masindi, Uganda. BMC Health Serv. Res. 2014, 14, 65. [CrossRef] [PubMed]

15. WHO; ICM; FIGO. Making Pregnancy Safer: The Critical Role of the Skilled Birth Attendant Geneva; World Health Organization: New York, NY, USA, 2004.

16. Ministry of Health and Public Assistance. Training Manual for Traditional Birth Attendants in Neonatal Maternal Care; Program, N.R.H., Ed.; Ministry of Health and Public Assistance: Guatemala City, Guatemala, 2016. 
17. Hernandez, S.; Oliveira, J.B.; Shirazian, T. How a training program is transforming the role of traditional birth attendants from cultural practitioners to unique health-care providers: A community case study in rural Guatemala. Front. Public Health 2017, 5. [CrossRef] [PubMed]

18. Hernandez, S.; Oliveira, J.; Cuc, J.C.; Shirazian, T. Prenatal Skills Pilot Study of Graduates from a Traditional Birth Attendant Training Program in Rural Guatemala; American College of Obstetrics and Gynecology: Austin, TX, USA, 2018.

19. McCord, C.; Premkumar, R.; Arole, S.; Arole, R. Efficient and effective emergency obstetric care in a rural Indian community where most deliveries are at home. Int. J. Gynaecol. Obstet. 2001, 75, 297-307. [CrossRef]

20. Jokhio, A.H.; Winter, H.R.; Cheng, K.K. An Intervention involving traditional birth attendants and perinatal and maternal mortality in Pakistan. N. Engl. J. Med. 2005, 352, 2091-2099. [CrossRef] [PubMed]

21. Spector, J.M.; Agrawal, P.; Kodkany, B.; Lipsitz, S.; Lashoher, A.; Dziekan, G.; Bahl, R.; Merialdi, M.; Mathai, M.; Lemer, C.; et al. Improving quality of care for maternal and newborn health: Prospective pilot study of the WHO safe childbirth checklist program. PLOS ONE 2012, 7, e35151. [CrossRef] [PubMed]

22. Patabendige, M.; Senanayake, H. Implementation of the WHO safe childbirth checklist program at a tertiary care setting in Sri Lanka: A developing country experience. BMC Pregnancy Childbirth 2015, 15, 12. [CrossRef] [PubMed]

23. True, B.A.; Cochrane, C.C.; Sleutel, M.R.; Newcomb, P.; Tullar, P.E.; Sammons, J.H., Jr. Developing and Testing a Vaginal Delivery Safety Checklist. J. Obstet. Gynecol. Neonatal. Nurs. 2016, 45, 239-249. [CrossRef] [PubMed]

24. Individualized, Supportive Care Key to Positive Childbirth Experience, Says WHO: World Health Organization 2018. Available online: http://www.who.int/mediacentre/news/releases/2018/positivechildbirth-experience/en/ (accessed on 16 February 2018).

25. Stollak, I.; Valdez, M.; Rivas, K.; Perry, H. Casas Maternas in the rural highlands of Guatemala: A Mixed-methods case study of the introduction and utilization of birthing facilities by an indigenous population. Glob. Health Sci. Pract. 2016, 4, 114-131. [CrossRef] [PubMed]

(C) 2018 by the authors. Licensee MDPI, Basel, Switzerland. This article is an open access article distributed under the terms and conditions of the Creative Commons Attribution (CC BY) license (http:/ / creativecommons.org/licenses/by/4.0/). 